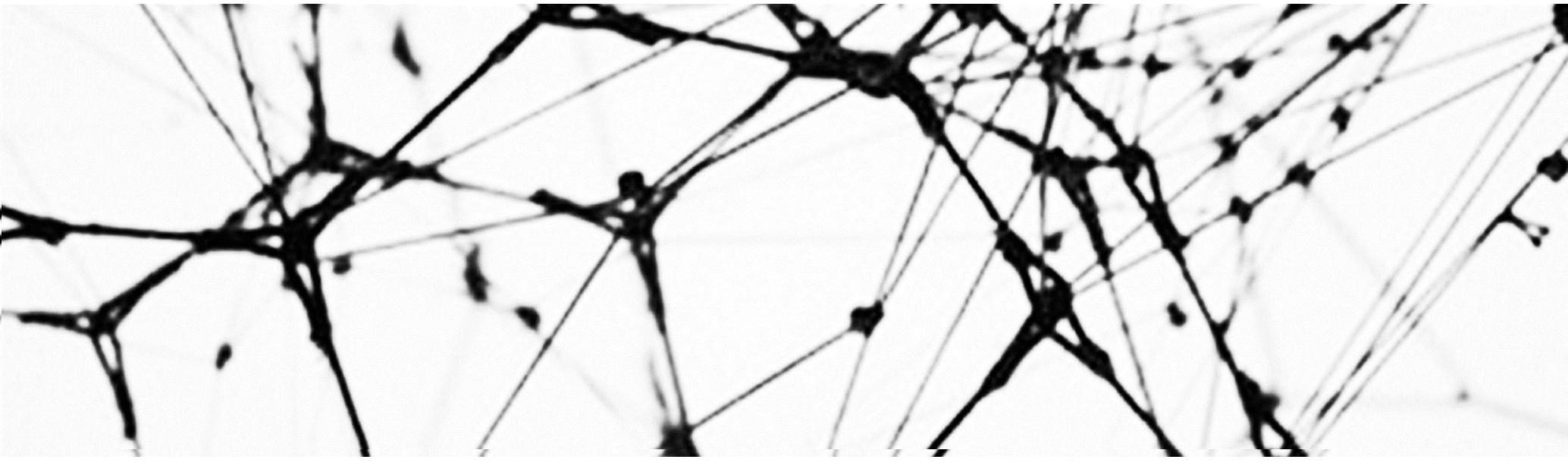

\title{
A FILOSOFIA NO SERTÃO: DA FORMAÇÃO DE PROFESSORES À FILOSOFIA NO ENSINO MÉDIO
}

\author{
FILOSOFIA EN EL "SERTÃO": DE LA FORMACIÓN DE \\ PROFESORES A LA FILOSOFIA EM LA ESCUELA SECUNDARIA
}

Prof. Dr. José Teixeira Neto ${ }^{1}$

Prof. Me. Emerson Araújo de Medeiros ${ }^{2}$

Prof. Me. José Francisco das Chagas de Souza ${ }^{3}$

"[...] desde 1968, Caicó acalentava o sonho de ter um Curso de Filosofia".

Resumo: No presente artigo, escrito a três mãos, pretendemos falar sobre a presença da Universidade do Estado do Rio Grande do Norte-UERN em Caicó - RN e, de modo mais específico, sobre a formação de professores para o componente curricular "filosofia no Ensino Médio" no Curso de Filosofia do Campus Caicó. Dividiremos o texto em três momentos: no primeiro, buscaremos traçar a história da presença da UERN em Caicó. No segundo momento, analisaremos os aspectos mais relevantes do componente curricular "filosofia no Ensino Médio". Por fim, apresentaremos os impactos do Programa Institucional de Bolsas de Iniciação à Docência-PIBID, principal programa que vem fortalecendo as licenciaturas no Brasil, na formação docente em Filosofia no Campus Caicó.

Palavras chaves: Formação de Professores. Filosofia no Ensino Médio. PIBID.

Resumen: En este artículo, escrito a tres manos, queremos hablar sobre la presencia de la Universidade do Estado de Rio Grande do Norte-UERN en Caicó - RN y, específicamente, hablar de la formación de maestros para la filosofía en la escuela secundaria. Dividiremos el texto en tres momentos: el primero, traza la historia de la

\footnotetext{
1 Professor Adjunto no Departamento de Filosofia da Universidade do Estado do Rio Grande do Norte, Campus Caicó. Professor do Mestrado Profissional em Filosofia (PROF-FILO) - Núcleo da UERN/Campus Caicó. E-mail: josteix@hotmail.com

2 Aluno de Mestrado Profissional em Filosofia (PROF-FILO) - Núcleo da UERN/Campus Caicó.

3 Professor do Curso de Filosofia do Campus Caicó-UERN. Atualmente, cursa o Doutorado em Letras, UERN - Pau dos Ferros-RN com pesquisa: "O discurso de Riobaldo em Grande Sertão: Veredas de Guimarães Rosa a partir da Fenomenologia da Linguagem de Merleau-Ponty". Revista Digital de Ensino de Filosofia - Santa Maria - vol.3. n. 1 - jan./jun. 2017.
} 


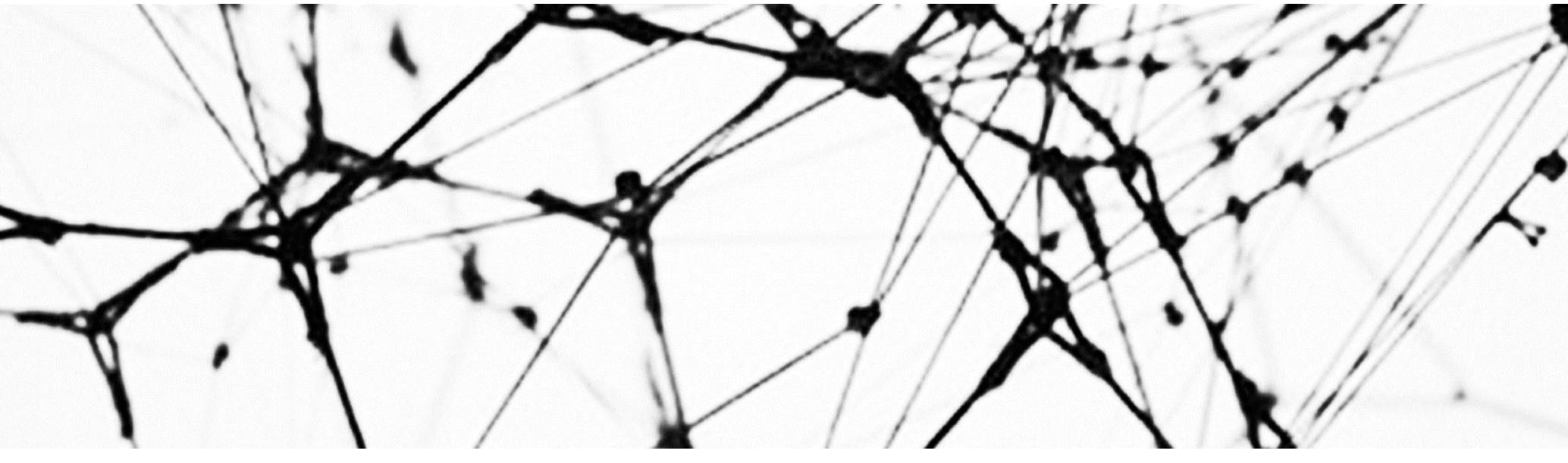

presencia de UERN en Caicó. En el segundo, analizaremos los aspectos más relevantes de la enseñanza de filosofía en la escuela secundaria. Por último, vamos a presentar los efectos del Programa Institucional de Bolsas de Iniciação à Docência-PIBID, principal programa en Brasil para fortalecimiento al fortalecimiento de la formación docente.

Palabras clave: Formación de maestros. Filosofía en la escuela secundaria. PIBID. 


\title{
1. O curso de filosofia da UERN em Caicó - RN
}

A história da educação do Seridó e, principalmente, em Caicó - RN se confunde com a história da presença da Igreja Católica nesse torrão do sertão potiguar. Prova disso é a Escola de Latim do Pe. Guerra ${ }^{4}$, a fundação do atual Colégio Diocesano Seridoense, antes Ginásio Diocesano Seridoense, em $1^{\circ}$ de março de 1942 pelo primeiro bispo da Diocese de Caicó, D. José de Medeiros Delgado5.

Já no que se refere ao ensino superior podemos destacar o que segue. De acordo com o Pe. João Medeiros "O dia 16 de dezembro de 1968 é um marco no ensino superior em Caicó e em todo o Seridó" (apud ROCHA, 2008, p. 135-136)6, pois foi quando

\begin{abstract}
O Prefeito Municipal, Bacharel Francisco de Assis Medeiros, sancionou uma lei municipal, criando a Fundação Educacional Dom José Delgado, que deveria ser mantenedora da futura Faculdade de Filosofia, Ciências e Letras de Caicó. [...]. Vale salientar que, antes mesmo do envio da mensagem à Câmara de Vereadores de Caicó, o Prefeito Municipal, Francisco de Assis Medeiros, o vice Prefeito, Dr. Vicente Macedo, e o Presidente da Câmara, Homero Alves de Medeiros, procuraram - Bispo Diocessano, Dom Manoel Tavares de Araújo, solicitando que a Diocese fosse a mantenedora e a patrocinadora da futura Faculdade. Diante da grande dificuldade econômica que passava a Diocese, Dom Tavares respondeu que, apesar da hora e da deferência para a diocese, pioneira no ensino e da educação da juventude seridoense, seria impossível o bispado assumir ingente tarefa. Prometeu, no entanto, [...] colaborar no projeto de implantação da futura faculdade. [...]. Vê-se, portanto, que desde 1968, Caicó acalentava o sonho de ter um Curso de Filosofia (Cursivo nosso).
\end{abstract}

Outro fato importante para o ensino superior no Seridó e que também tem a participação direta da Diocese é a criação do Núcleo Avançado de Caicó da Universidade Federal do Rio Grande do Norte-UFRN. Em 19737,

\footnotetext{
4 Conferir:

http://adcon.rn.gov.br/ACERVO/secretaria_extraordinaria_de_cultura/DOC/DOC0000000001083 55.PDF

5 Conferir: http://www.coscaico.com.br/institucional/historia

6 ROCHA, Jaime Vieira (Bispo diocesano). Liber vi spiritus (Liberdade pela força do espírito). Trilhas filosóficas. Ano 1. Nº 1. Jan/Jun 2008, p. 134-139.

7 Pe. João Medeiros (apud ROCHA, 2008, p. 136-137), sobre a criação do Núcleo Avançado de Caicó da UFRN, afirma o seguinte: 'Estávamos em 1973. Houve um momento histórico político, uma coincidência que teve a mão da Providência. Somos pessoas de fé! Era reitor da UFRN, Genário Alves Fonseca, cujo mandato terminaria em 1974. Ele acalentava o sonho e desejo de Revista Digital de Ensino de Filosofia - Santa Maria - vol.3. n. 1 - jan./jun. 2017.
} 
através do sistema multicampi, a UFRN iniciou sua expansão para o interior do Estado e o Núcleo Avançado de Caicó constituiu a primeira experiência dessa natureza.8 Qual a participação da Diocese de Caicó nesse fato específico? Novamente Pe. João Medeiros (apud ROCHA, 2008, p. 137) relata:

Muita coisa não teria sido feita sem a colaboração e, sobretudo, compreensão da Diocese. O prédio do antigo Seminário foi cedido sem ônus à Universidade para ali funcionar até a construção da futura sede, o núcleo e a casa do professor itinerante. A universidade e as prefeituras da Diocese liberaram recursos para a recuperação do prédio. Outra participação importante da Diocese foi um convênio assinado para manter o pessoal técnico e de apoio. É importante frisar que o MEC não abria concurso para o pessoal administrativo, mas liberava recursos para a prestação de serviço por pessoas jurídicas. Foi celebrado um convênio assinado entre a Universidade e o DDAS (Departamento Diocesano de Ação Social) para o pagamento do pessoal técnico e de apoio. [...].

Outro grande gesto de participação e grandeza da Diocese foi a liberação do Pe. José Mário para substituir o Pe. João Medeiros que adoecera e tivera que se transferir para o Rio de Janeiro. Caberia ao Pe. José Mário e a seus sucessores a expansão do núcleo, que se transformou em Centro de Estudos Autônomo, com dotação orçamentária própria e acento nos Conselhos Superiores da Universidade. Pe. José Mário teve papel decisivo para a implantação de outro Campus no Seridó, em Currais Novos. Procurou aquele sacerdote revitalizar - Campus do Seridó quando o reitor Diógenes da Cunha Lima, seu amigo, o nomeou Diretor Geral do Campus, cargo que em outras universidades é chamado Pró-Reitor de Interiorização.

Já com relação à presença da Universidade do Estado do Rio Grande do Norte-UERN em Caicó a Diocese caicoense também teve papel

tornar seu sucessor o professor Domingos Gomes de Lima (ex-colega de turma e de seminário do Pe. João Medeiros). O professor necessitava do apoio político em Brasília do então ministro da Educação Jarbas Passarinho. Diante da amizade do Senador Dinarte Mariz com o ministro, 0 Reitor Genário pediu apoio ao Senador Caicoense. A reposta foi positiva com uma única condição: que a UFRN levasse para Caicó alguns cursos de nível superior. O ministro liberaria verbas necessárias para a implantação. Dinarte procurou recuperar o prestígio político em Caicó e no Seridó por conta do último [1972] pleito municipal. O acordo acadêmico-político foi celebrado. O senador Dinarte Mariz impôs mais uma condição: que os trabalhos fossem entregues à direção da diocese (e fossem retirados das mãos dos políticos). Domingos Gomes de Lima, ainda Pró-Reitor de Administração, pediu ao bispo Diocesano de Caicó que liberasse o Pe. João Medeiros para coordenar os trabalhos [...]. Assim em 1973 o conselho universitário da UFRN criou o núcleo avançado de Caicó (sic.) e o conselho de Ensino e Pesquisa - o CONSEPE criou o ciclo básico da área humanista para funcionar em Caicó a partir de março de 1974. As obras da futura sede do núcleo começaram. O concurso para docentes foi realizado, tendo sido aprovados: Pe. Ausônio Tércio de Araújo, Pe. João Agripino Dantas, Ir. Pauline (da Comunidade Religiosa de Jardim de Piranhas), Nildo João Matias Alff e Levi Higino Jales, ambos juízes de direito em Caicó e, posteriormente, Pe. José Mário de Medeiros, liberado para ser o primeiro diretor".

8 Conferir: http://www.cerescaico.ufrn.br/ceres/historia-do-centro/

Revista Digital de Ensino de Filosofia - Santa Maria - vol.3. n. 1 - jan./jun. 2017. 
importante. Desde 1999 funcionava nas dependências do Colégio Diocesano Seridoense-CDS o Instituto de Teologia Pastoral Cardeal Sales ${ }^{9}$ que oferecia o Curso Eclesiástico de Filosofia. O curso em questão não era reconhecido pelo Ministério da Educação; não era gratuito; a maior parte dos alunos era de leigos ligados às paróquias da Diocese, seminaristas e quase todos os professores eram padres.

Porém, graças ao interesse e à visão social de D. Jaime Vieira Rocha, quinto Bispo de Caicó (1995-2005) e atual Arcebispo da Arquidiocese de Natal, a Diocese de Caicó propôs que a UERN incorporasse à sua estrutura acadêmica o curso eclesiástico oferecido pelo Instituto Cardeal Sales. O Projeto Pedagógico do Curso de Filosofia do Campus Caicó, afirma que

Aos dezenove dias do mês de abril de 2001, o Departamento de Filosofia da Universidade do Estado do Rio Grande do NorteUERN/Mossoró, considerando a solicitação do Magnífico Reitor Prof. José Walter da Fonseca, deliberou por constituir uma comissão para analisar a possibilidade de incorporação, pela UERN, do Curso de Filosofia Eclesiástica do Instituto de Filosofia e Teologia Cardeal Sales da Diocese de Caicó, ministrado no Colégio Diocesano Seridoense - CDS daquela cidade. Naquele momento levou-se em consideração, principalmente, o anseio comum de todos os docentes presentes, em criar o Curso de Filosofia, em Mossoró.

Uma vez criada pelo Reitor a comissão proposta pelo Departamento, os docentes indicados - Antônio Jorge Soares, João Batista Xavier e William Coêlho de Oliveira -, imbuídos daquele anseio coletivo, investiram na análise da proposta de incorporação, juntamente com Francisco de Assis Costa da Silva, o Pe. Costa, representante da instituição caicoense, como Reitor do Seminário Diocesano Santo Cura d'Ars e Coordenador Administrativo do Curso em apreço. (PPC 2012. Curso de Filosofia).

\footnotetext{
9 "Atenta à sua vocação educacional e às condições favoráveis do clero diocesano pelo crescimento das vocações sacerdotais, bem como a demanda da cidade de Caicó e da região do Seridó para cursos de nível superior, a diocese de Caicó deu um passo adiante na direção do ensino de terceiro grau, marcando uma nova época com a criação do Instituto de Teologia Pastoral Cardeal Eugênio Sales e nele abrigava os cursos superiores (apesar de livres) de Filosofia e de Teologia. Tal iniciativa se fez realidade no dia $1^{\circ}$ de fevereiro de $1999 \mathrm{com}$ a Aula Inaugural, no auditório do Centro Pastoral Dom Wagner, proferida pelo ilustre e venerável monge Beneditino do Mosteiro de São Bento do Rio de Janeiro, Estevão Bitencurt. No Decreto de Criação do referido Instituto, entre outras normas, encontramos as seguintes: 1. 'Os cursos de Filosofia e Teologia serão ministrados em nível superior, mesmo ainda não reconhecidos pelos órgãos do Ministério da Educação, na qualidade de cursos chamados seminarísticos ou livres'. 2. 'A diocese envidará todos os esforços a fim de solicitar oportunamente credenciamento e autorização para ministrar cursos oficiais em Filosofia e Teologia ou ciências afins, de acordo com a legislação em vigor" (Pe. João Medeiros apud ROCHA, 2008, p. 137-138). Revista Digital de Ensino de Filosofia - Santa Maria - vol.3. n. 1 - jan./jun. 2017.
} 
Depois de analisadas as estruturas e dependências do CDS, a estrutura curricular vigente no Curso Eclesiástico e o elenco docente considerou-se não só a possibilidade de se incorporar o curso de Caicó, mas também de se criar um Curso de Filosofia também no Campus Central em Mossoró 10. Assim, decidiu-se por se firmar um convênio entre a UERN e a Diocese de Caicó. Os professores do Departamento de Filosofia de Mossoró ficaram responsáveis pela elaboração do Projeto Pedagógico do Curso de Licenciatura em Filosofia, no intuito de incorporar o Curso de Filosofia Eclesiástica. Dessa forma, - Curso de Licenciatura em Filosofia de Caicó, funcionou nas dependências do CDS durante o período de 2002.1 a 2005.2.

Em seu Discurso em Homenagem aos formandos do Curso de Licenciatura Plena em Filosofia UERN/Caicó proferido no dia 28 de julho de 2005, por ocasião da formatura da primeira turma concluinte do antigo Curso de Filosofia Eclesiástico, João Batista Xavier (2008, p. 132-133)11 faz "[...] homenagem a todos aqueles que contribuíram para a consolidação [...] do convênio assinado pelo Governo do Estado, a Diocese de Caicó e a Universidade do Estado do Rio Grande do Norte":

\begin{abstract}
Agradeço a Dom Jaime Vieira Rocha, Mons. Ausônio Tércio de Araújo, Reitor José Wlater Fonseca, Vice Reitora Olga Oliveira, Padre Francisco de Assis Costa da Silva, Padre José Tadeu, aos meus colegas professores do departamento de filosofia que confiaram a minha pessoa tamanha responsabilidade para que enquadrasse o curso de filosofia eclesiástica da Diocese de Caicó às normas da UERN, e em seguida nomeado coordenador pedagógico com a incumbência de realizar o processo de incorporação.
\end{abstract}

Meu reconhecimento ao trabalho abnegado dos professores associados, José Tadeu, [...], Everaldo de Araújo, Emerson [Araújo de Medeiros], José Teixeira Neto, [...], Fátima Gomes; Graça Leal; Ivanaldo Oliveira; [...]; José Francisco (Deda), José

\footnotetext{
10 Embora em Mossoró, Campus Central da UERN, existisse um departamento de filosofia, não existia, contudo, o curso de filosofia.

11 XAVIER, João Batista. Discurso em Homenagem aos formandos do Curso de Licenciatura Plena em Filosofia UERN/Caicó - 28/07/2005. Trilhas filosóficas. Ano 1. № 1. Jan/Jun 2008, p. 128-133. 0 Prof. João Batista Xavier, em 03 de dezembro 2012, proferiu outro discurso retomando a história da UERN em Caicó e indicando os desafios da Universidade no Seridó. Conferir: XAVIER, João Batista. Discurso proferido por ocasião da homenagem recebido do Curso de Filosofia/Caicó 03/12/2012. In. BRITO, Sueny Nóbrega Soares; CIRINO, Maria Reilta Dantas; SOUZA, José Francisco de Souza; TEIXEIRA NETO, José. Anais. V Semana de Filosofia do Campus Caicó. II JENFIC Jornada de Ensino de Filosofia de Caicó. Mossoró-RN: Edições UERN, 2013, p. 9-15. Disponível em: http://www.vern.br/controledepaginas/fisolofia-caico-

eventos/arquivos/2087anais_v_semana_de_filosofia.pdf > Acesso em: 02.04.2015.

Revista Digital de Ensino de Filosofia - Santa Maria - vol.3. n. 1 - jan./jun. 2017.
} 
Eudo, Francisco Borges, Alexandro Araújo de Medeiros, que contribuíram substancialmente para consolidar a primeira etapa deste projeto.

Na mesma ocasião, D. Jaime Vieira Rocha (2008, p. 134), assim se expressa com muita emoção e reconhecimento:

De Atenas, berço da filosofia e do pensamento humano, para Caicó, sertão do Seridó, semi-árido nordestino. Quem diria, podemos hoje em Caicó abrir uma janela a mais para a formação universitária e estabelecermos uma base de estudos e reflexões filosóficas a nos deparar com os conceitos mais abstratos e elevados [...]. Vivemos, portanto, a alegria de uma conquista, de uma vitória, nesta noite acadêmica de colação de grau da primeira turma de formandos do Curso de Licenciatura Plena em Filosofia [...]. Por isso, podemos até fazer presente e atual a pergunta de Tertuliano, filósofo cristão da antiguidade, século III, e contida agora mais recentemente no capítulo IV da Carta Encíclica Fides et Ratio (sic.) de João Paulo II: 'Que têm em comum Atenas e Jerusalém?'. Ou ainda de minha parte: Faculdade de Filosofia e a Diocese de Caicó?

Até 2014 o Curso de Filosofia já havia formado mais de 130 professores de filosofia. Desses egressos alguns já fizeram capacitação em nível de especialização, mestrado e doutorado; muitos atuam na rede básica nos Estados do Rio Grande do Norte e da Paraíba; outros também são docentes do nível superior. O corpo docente atual é formado por mestres e doutores, atuando ou em capacitação; os professores estão vinculados aos Grupos de Pesquisa Filosofia e Educação e Ensinar e Aprender na Educação Básica, ambos certificados pelo CNPq (linhas: Filosofia antiga e medieval; Filosofia e ensino; Ética e educação; Experiências de aprender e ensinar na educação básica) e desenvolvem pesquisas em ensino de filosofia, filosofia antiga, medieval, moderna e contemporânea. São diversos projetos de pesquisa institucionalizados ou que concorrem aos editas do Programa Institucional de Bolsas de Iniciação Científica (CNPq/UERN). Os principais eventos desenvolvidos pelo curso são: Semana de Filosofia do Campus Caicó (VII Semana em 2016); SInFiC - Semana Interna de Filosofia de Caicó (VI edição em 2015); JENFIC - Jornadas de Ensino de Filosofia de Caicó (V edição em 2016); Ciclo de Estudos Curriculares (II edição em 2013); Semana Universitária (VII em 2015); Fórum de Licenciaturas (2014).12 Por fim, como mostraremos no terceiro momento, o Curso de Filosofia do Campus Caicó conta com o Programa

12 Conferir: http://caico.vern.br/dfi/default.asp?item=curso-filosofia-caico-apresentacao Revista Digital de Ensino de Filosofia - Santa Maria - vol.3. n.1 - jan./jun. 2017. 
Institucional de Bolsas de Iniciação à Docência-PIBID. Os bolsistas do PIBID estão inseridos em três escolas de Ensino Médio de Caicó: EECCAM-Escola Estadual Calpúrnia Caldas de Amorim (2 Supervisores e 10 bolsistas); EEAAEscola Estadual Antônio Aladim (1 Supervisor e 5 bolsistas) e CEJA-Centro Educacional José Augusto (1 Supervisor e 5 bolsistas). ${ }^{13}$

\section{Retratos da filosofia no ensino médio}

Após relatarmos alguns dos aspectos mais relevantes da história da presença da UERN e do Curso de Filosofia em Caicó, abordaremos em seguida, alguns elementos mais teóricos sobre o componente curricular "Filosofia no Ensino Médio". O ensino de Filosofia sempre esteve presente ao longo de toda história da Filosofia. Com os Sofistas (metade do sec. V a.C.): "O ensino da filosofia ganha uma vinculação com a aquisição de técnicas retóricas para o uso político". (SOFISTE, 2007, P. 9) ${ }^{14}$. Eles são os primeiros professores remunerados, mas receberam fortes críticas de Sócrates, Platão e Aristóteles que os acusavam de "vender" o saber. Estes acreditavam que a Filosofia era um exercício a ser praticado nas ruas e também na própria academia de forma não remunerada. O ensino da Filosofia, portanto, é indissociável da sua história. Na àgora ${ }^{15}$ em Atenas, nas academias, nos "jardins", nas escolas medievais, nas permutas dos escritos da modernidade ou mesmo na contemporaneidade nas suas diversas práticas nos currículos das instituições em todo o mundo. Percorrendo todo esse caminho até aportar no Brasil, como herança do "velho mundo" com seus métodos e influências. E aqui, foram muitos os "vai-e-vem" da Filosofia até se tornar presença efetiva nos currículos escolares, seja do ensino médio ou nas instituições superiores. $\bigcirc$ fato é que vivemos um novo tempo propício para se pensar esta presença nos currículos e os desafios a serem enfrentados por todos os envolvidos com o ensino desta.

\footnotetext{
${ }^{13}$ Conferir: http://www.pibidfilosofiacaico.com/

${ }^{14}$ SOFISTE, J.G. Sócrates e o ensino de Filosofia. Investigação dialógica numa pedagogia para a docência de Filosofia. Petrópolis, RJ: Vozes, 2007.

${ }^{15}$ Mercado de Atenas ou local de espaço pública das praças onde Sócrates discutia com os jovens.

Revista Digital de Ensino de Filosofia - Santa Maria - vol.3. n.1 - jan./jun. 2017.
} 
A presença da filosofia no Ensino Médio se justifica essencialmente quando consideramos que os alunos da educação básica se encontram em pleno desenvolvimento psíquico e intelectual nesse período e que eles se inserem no processo de construção e de formação da própria consciência. Esse é um momento propício para a aprendizagem e aguçamento crítico e reflexivo de questões, argumentos e métodos de pensamento. A edificação intelectual do jovem da educação básica segue seu processo natural de desenvolvimento do pensamento e das faculdades intelectuais desse período de suas vidas, trazendo como consequência benéfica a atitude frente às questões fundamentais que permeiam a existência humana.

Qual a atitude que o professor de filosofia deve assumir frente aos questionamentos sobre a importância da filosofia como disciplina obrigatória da grade curricular da educação básica? Sabemos que parte dos alunos e também o próprio sistema escolar preferem as disciplinas das áreas de ciências exatas, biológicas, linguísticas e da natureza. Mas, o professor de filosofia deve estar adequadamente habilitado para que possa envolver os alunos e mostrar-Ihes que estudar filosofia não significa simplesmente contar histórias sobre o passado. É necessário revelar e expor que a filosofia tem a ver com a vida cotidiana de cada um e que os discentes podem ser protagonistas da sua própria história de vida inserida no contexto social, cultural, político, ético, histórico e econômico. Nossos alunos devem ser encorajados ao pensamento crítico, ao debate e a reflexão sobre os problemas existenciais. Essa prerrogativa não exclui o conhecimento e o aprofundamento daqueles que contribuíram com a formação do pensamento no decorrer dos séculos, ou seja, dos filósofos que foram capazes de buscar respostas para os mais diversos e variados problemas. Dessa forma, "a Filosofia é fundamentalmente, uma modalidade de conhecimento mediante a qual pretendemos conhecer algo a respeito dos diversos aspectos da realidade, exatamente naquilo que concerne à nossa relação com o mundo no qual nos encontramos situados". (SEVERINO, 2013, p. 3) ${ }^{16}$.

16 SEVERINO, Antônio Joaquim. Como ler um texto de filosofia. 4ed. São Paulo: Paulus, 2013. Revista Digital de Ensino de Filosofia - Santa Maria - vol.3. n.1 - jan./jun. 2017. 
A Filosofia no Ensino Médio deve ser capaz de propiciar aos nossos discentes a formulação de um pensamento claro, uma maior compreensão na interpretação dos textos, conhecimento de conteúdos específicos pertencentes à história da própria filosofia e de fornecer um diálogo permanente com as outras áreas do saber científico.

Durante décadas a Filosofia não fez parte do currículo nacional de educação. Essa ausência, bastante sentida ainda hoje, deixou uma lacuna e que no presente boa parte dos estudos realizados tenta justificar a sua valia e necessidade, como também, orientar os professores e alunos a encontrarem saídas e soluções para um maior enraizamento dessa disciplina na educação básica. O percurso tem sido longo, mas tem mostrado frutos, basta ver o material didático que dispomos, a quantidade de pesquisas sobre o tema, publicações e orientações curriculares.

Atentos ao processo histórico brasileiro identificamos algumas fases históricas bem definidas e distintas no que concerne à presença da filosofia no Brasil (ALVES, 2009) ${ }^{17}$. No período colonial se buscou catequizar os indígenas e africanos como também manter os colonos sob os olhos da Igreja Católica e nesse período houve um pouco de confusão entre filosofia e ensino religioso. Posteriormente para prover as classes mais privilegiadas do ponto de vista econômico, se buscou uma educação nos moldes da metrópole, ou seja, intermitente (CAMPANER, 2012) ${ }^{18}$.

Com o passar dos tempos, já que não nos deteremos ao processo histórico minuciosamente, no ano de 1971, se retira do currículo a disciplina de filosofia no contexto da reforma considerada tecnicista, empreendendo assim, por parte dos departamentos de filosofia das universidades brasileiras uma crítica, quanto a sua retirada e defesa do seu retorno. Nos meados de 1980, esse movimento veio a ter um êxito parcial quando foi aprovada a inclusão da filosofia como componente opcional. Isso influenciou os debates acerca da elaboração da criação da Lei de Diretrizes e Bases da Educação Nacional

\footnotetext{
17 ALVES, Dalton José. A filosofia como matéria de ensino: história e questões metodológicas. Publ. UEPG Humanit. Sci., Appl. Soc. Sci., Linguist., Lett. Arts, Ponta Grossa, 17 (2): 177-187, dez. 2009. Disponível em: <http://www.revistas2.vepg.br/index.php/humanas/article/view/1771>. 18 CAMPANER, Sônia. Filosofia: ensinar e aprender. São Paulo: Saraiva, 2012. Revista Digital de Ensino de Filosofia - Santa Maria - vol.3. n. 1 - jan./jun. 2017.
} 
(LDB), e em seguida a promulgação da Constituição Federal de 1988. O projeto aprovado na Constituição Federal previa a filosofia e a sociologia como disciplinas obrigatórias. Contudo, o Substitutivo Darci Ribeiro (flexível e minimalista), aprovado posteriormente como lei n. 9.394/96, faz uma opção pela filosofia e sociologia como conhecimentos obrigatórios, mas não define o seu caráter disciplinar. O Ministério da Educação, na gestão do Sr. Paulo Renato de Sousa, dá a essas disciplinas o caráter de "temas transversais", e não as tratou como disciplina, tanto que na época o presidente Fernando Henrique Cardoso veta o projeto de lei de autoria do dep. Pe. Roque Zimmermann que buscava alterar a LDB e classificar a filosofia e a sociologia como disciplinas obrigatórias do currículo nacional. Com o término do governo do então sociólogo e presidente Fernando Henrique Cardoso as articulações foram reiniciadas, vindo a ser aprovadas pela Câmara e o Senado e sancionada no ano de 2008 pelo então presidente Luís Inácio Lula da Silva (RODRIGO, 2014) ${ }^{19}$.

Parte dos professores de Filosofia no Ensino Médio quando está organizando e estudando o conteúdo programático, coloca a seguinte questão: "ensinar o quê?". Partindo dessa perspectiva, devemos ser e pensar como uma espécie de sismógrafo sensível do ponto de vista intelectual, capazes de captar possíveis mudanças e variações na condução do processo ensino aprendizagem em curso. Quando propomos temas, estudos e reflexões em sala de aula, devemos estar atentos à ligação entre contextos e perspectivas a serem abordadas.

O encadeamento do processo de filosofar parte da sensibilização e problematização da experiência vivida e o ensino aprendizagem nessa área do saber científico só existem quando se rompe com o cotidiano das pessoas, com tudo aquilo que é rotineiro, óbvio e conhecido. É o não ao senso comum, a tudo aquilo que foi dito e ensinado pelos nossos pais e antepassados e que

\footnotetext{
19 RODRIGO, Lídia Maria. Filosofia em sala de aula: teoria e prática para o ensino. 2 ed. Campinas: Autores Associados, 2014. (Coleção formação de professores). Contudo, novamente a presença da filosofia na educação está ameaçada tendo em vista a lei 13.415: BRASIL. Lei $n^{\circ}$ 13.415, de 16 de fevereiro de 2017. Disponível em: <http://www.planalto.gov.br/ccivil_03/_Ato2015-2018/2017/Lei/L13415.htm\#artl> Acesso em: 15/06/2017 (Altera as Leis nos 9.394, de 20 de dezembro de 1996, que estabelece as diretrizes e bases da educação nacional, ...).

Revista Digital de Ensino de Filosofia - Santa Maria - vol.3. n. 1 - jan./jun. 2017.
} 
parece ser claro (SOUZA, 2004) ${ }^{20}$. Somos incentivados a repensar nossos próprios pensamentos e ações e trilhar novos caminhos na busca incessante pela maturidade intelectual e humana. O nosso aluno deve abandonar o comportamento ingênuo e assumir uma postura interrogativa, capaz de buscar respostas e significação para a sua existência.

Outro desafio é "ensinar para quê?". Aqui, gostaríamos de chamar a atenção para o fato de que ela por si só é detentora de uma riquíssima gama de conhecimentos e contribui diretamente para alargar o horizonte intelectual de todos aqueles que buscam o saber. Nela encontramos diversas áreas, tais como: metafísica, moral, política, ciências, história, lógica, estética e linguagem. É nesse processo que temos a oportunidade de abordar, na educação básica, temas relevantes para a vida individual e coletiva das pessoas, e com isso contribuir na edificação de cidadãos mais conscientes e conhecedores de seus direitos e deveres.

O ensino de Filosofia exige do aluno um melhor raciocínio, postura crítica, problematizar o cotidiano, formular e reformular os próprios questionamentos, enxergar com mais clareza a verdade que se esconde por trás da realidade, estar atento às ideologias e a formular os conceitos. Outro ponto importante é a apropriação de textos com suas respectivas interpretações, o primar pela comunicação e pelo domínio fluente da leitura com todas as suas variantes. Enfim, suscitar no aluno o desejo de romper com as amarras de toda e qualquer vida que o aprisione quanto à formação da consciência. Outro grande desafio é aquele que talvez exija mais cuidado e atenção: "como ensinar"? Essa pergunta sintetiza aquela relação entre teoria e prática com vistas a alcançar resultados na sala de aula edificando e construindo saberes.

Em nossas pesquisas encontramos (SOUZA, 2004) dois modos de lidar com a questão. O primeiro seria a filosofia como resposta ou produto e o segundo a filosofia como questão ou processo. O primeiro seria a aquisição de um saber pronto, de memória e o segundo seria visto como um aprender a

20 SOUZA, Sônia Maria Ribeiro de. A filosofia no ensino médio: Uma (re)leitura a partir dos PCNs. In: GALLO, Sílvio; DANELON, Márcio; CORNELLI, Gabriele (orgs). Ensino de Filosofia: Teoria e prática. ljuí (RS): UNIJUí, 2004. pág. 161-181.

Revista Digital de Ensino de Filosofia - Santa Maria - vol.3. n. 1 - jan./jun. 2017. 
pensar, a questionar e porque não dizer o ato de filosofar. É esse o nosso ponto focal, romper com a cotidianidade e estimular os jovens estudantes de filosofia a perceberem que o mundo real pode ser a porta principal para ingresso na filosofia. Devemos inserir leituras e análises de obras filosóficas que revelem o pensamento do autor e que possa nos servir de guia (primeiro olhar) diante da discussão e debate proposto. Assim seremos capazes de levar esse aluno a reavaliar, refletir e analisar seus próprios problemas e indagações e tentar trazer uma compreensão nova que clareie sua caminhada de vida.

A identidade da disciplina, a interação entre aluno e professor, métodos didático-pedagógicos adequados, aulas expositivas dialogadas, a leitura e análise de textos, domínio da linguagem e familiaridade com os procedimentos de análise filosófica empregados no processo de ensino e aprendizagem (SOUZA, 2004). Todos devem embarcar nessa viagem de significados, é um caminho sem volta e de construção de significados.

Por fim, devemos nos indagar sobre "para quem ensinar"? Esse é outro desafio por exigir uma acurada sensibilidade por parte do professor em enxergar com lucidez a sua clientela e tudo aquilo que está em torno dela, especialmente as mudanças que estão em curso na nossa sociedade.

As condições de vida atual são totalmente diferentes daquelas de uma década atrás. O professor hoje compete em audiência com as novelas, com a internet, com a mídia eletrônica, os meios de comunicação, as redes sociais etc. A boa leitura é substituída pelos atrativos do cinema, da televisão, dos DVDs, do vídeo game, dos celulares. Isso e muito mais podem fazer com que o aluno fique alheio à leitura e às interpretações de textos e à redação provocando uma linguagem falada sem vocabulário, deficiência na escrita e dificuldade de interpretar textos. "E o ensino de filosofia é, basicamente, uma construção subjetiva, apoiada em uma série de elementos objetivos e conjunturais. Um bom professor [...] será aquele que possa levar adiante, de forma ativa e criativa, essa construção" (CERLETTI, 2009, p. 8)21, mesmo nessas situações adversas.

${ }^{21}$ CERLETTI, Alejandro. O ensino de filosofia: como problema filosófico. Belo Horizonte: Autêntica, 2008.

Revista Digital de Ensino de Filosofia - Santa Maria - vol.3. n.1 - jan./jun. 2017. 
Antônio J. Severino (2014, p. 11-12)22 em entrevista concedida a Jorge da Cunha Dutra e Fábio Antônio Gabriel para a revista Filosofia assim responde:

FILOSOFIA - No atual cenário brasileiro, em que a disciplina de Filosofia é valorizada no currículo do ensino médio, de que modo acreditas que ela pode contribuir para a formação dos estudantes?

SEVERINO - Como modalidade de conhecimento destinada a explicitar os sentidos das práticas humanas, a Filosofia se faz necessária em qualquer etapa de nossa existência. [...]. Nesse nível de ensino, o seu papel é o de subsidiar o adolescente para que ele se entenda no contexto do mundo em que vive. O objetivo é levá-lo à experiência do refletir filosófico, como via de acesso ao sentido de sua existência no contexto da existência humana em geral. [...]. O que se visa é subsidiar os adolescentes com vistas à conquista e à prática do exercício de uma reflexão capaz de assegurar-lhes com autonomia e consistência, uma compreensão mais segura dos sentidos, conceituais e valorativos, que norteiam sua prática e, consequentemente, sua existência, sem descontextualizá-la diante das condições históricas onde ela se desenrola. [...] subsidiar o sujeito educando a ressignificar sua experiência do mundo.

É um trabalho lento e duradouro capaz de intercalar teoria e prática, ser e não-ser, tempestade e calmaria principalmente no tocante "o radical comprometimento com o real, com este mundo atual, com o aqui e agora, do qual ela concomitantemente se distancia e se afasta - estranho este aproximar-se à medida que se afasta e afastar-se à medida que se aproxima" (FOGEL, 2009, p. 25) 23. Enfim, deve haver dedicação, respeito e amor para que o trabalho seja fecundo e eficaz, caso contrário, nenhum mestre, por mais culto que seja, será capaz de apresentar uma proposta de estudo eficiente e eficaz. Somente assim ele terá as condições de olhar o passado com os olhos do presente numa dimensão de futuro que está por construir.

Por conseguinte, devemos fazer um esforço complexo com intuito de desenvolvermos ferramentas capazes de alavancar e melhorar o nível de aprendizagem e integração que ainda nos encontramos.

22 SEVERINO, Antônio Joaquim. Filosofia para a vida. Filosofia Ciência e Vida, São Paulo, v. 08, n. 98, pág. 05-13, set. 2014. Entrevista concedida a Jorge da Cunha Dutra e Fábio Antônio Gabriel. ${ }^{23}$ FOGEL, Gilvan, Que é Filosofia?: Filosofia como exercício de finitude. Aparecida (SP): Ideias e Letras, 2009.

Revista Digital de Ensino de Filosofia - Santa Maria - vol.3. n.1 - jan./jun. 2017. 
O desafio consiste em inventar uma prática de modo que o aprendizado de filosofia faça sentido para os jovens estudantes. Só assim a inclusão da disciplina nos currículos poderá efetivar-se e consolidar-se. Ao contrário, experiências desastrosas neste momento podem levar em médio prazo, a uma retirada dos currículos, desta vez justificada pelo fato de a disciplina não ter conseguido mostrar a que veio. (RODRIGO, 2014, p. XI)

Por fim, concluímos que responder às questões levantadas anteriormente exige sintonia com os anseios atuais da juventude e que a contribuição da filosofia para o Ensino Médio é de grande valia à medida que suscita a reflexão e as indagações frente às questões existenciais. Além disso, é um fato que o debate em torno da filosofia na educação básica está em plena efervescência, haja vista as inúmeras publicações, debates e palestras em torno da sua identidade, desafios e perspectivas. Porém, embora a Filosofia possua uma identidade e especificidade no Ensino Médio, ainda é necessário avançar nas práticas e nas metodologias próprias para esse nível de ensino.

\section{A presença do PIBID de filosofia em Caicó - RN}

A presença de uma licenciatura em Filosofia na região do Seridó através da UERN, como vimos, já era uma realidade desde 2001, porém, em 2008, institucionalizamos um Projeto de Pesquisa ${ }^{24}$ que tinha como objetivo traçar um perfil do ensino de Filosofia em Caicó. Esse foi o primeiro passo com uma preocupação realmente voltada para a docência. Assim que entrou em vigor a lei 11.684 de 2 de junho de 2008, sobre a obrigatoriedade do ensino de Filosofia e Sociologia no ensino médio, nós do Curso de Filosofia de Caicó, especialmente os bolsistas do PIBID, iniciamos estudos a partir dos depoimentos e escritos de professores que já empreendiam a luta pelo retorno da disciplina de Filosofia no Brasil.

Quando a Universidade do Estado do Rio Grande do Norte - UERN foi incluída entre as Instituições de ensino superior a integrar o PIBID, dentre os seis

\footnotetext{
24 Filosofia no ensino médio - Elaborando um perfil. Concluído em 2009, vide relatório final, produções científicas sobre o tema e anexos. O Projeto culminou com um evento denominado I JENFIC (Jornada de Ensino de Filosofia de Caicó) para socialização dos resultados. Revista Digital de Ensino de Filosofia - Santa Maria - vol.3. n. 1 - jan./jun. 2017.
} 
subprojetos apresentados na ocasião, estava o nosso de Filosofia do Campus Caicó. Pensado e elaborado por um grupo de professores, Maria Reilta Dantas Cirino, Galileu Galilei Medeiros de Souza e José Francisco das Chagas de Souza, docentes do citado curso, aprovado, foi dado início naquela ocasião, ano de 2009, tendo sido escolhido para Coordenador de Área o professor José Francisco das Chagas Souza. Em 2013 o Curso de Filosofia do Campus Caicó voltou a aprovar o subprojeto no Edital PIBID 061/2013 para o qual foi escolhido como Coordenador de Área o projeto José Teixeira Neto.

Se em 2009 foram aprovadas dez vagas de bolsista e uma para supervisor, em 2013 o projeto se estendeu para 20 vagas de bolsistas, 04 supervisores e com atuação em três escolas do Ensino Médio. Procedeu-se, em ambas as edições, a seleção de alunos-bolsistas para preenchimento das vagas a que tínhamos direito. O primeiro momento do subprojeto fora dedicado aos estudos como embasamento teórico precedendo a intervenção na Escola campo de ação. O referido momento serviu como importante suporte e conhecimento da realidade das escolas, do curso de Filosofia e de fundamentação legal, além de estudos de textos específicos da docência.

Antes de qualquer atuação nas escolas parceiras do subprojeto de Filosofia, dedicamos os primeiros semestres de 2010 e 2014 a estudos de embasamentos teóricos a partir de textos clássicos da Filosofia e de textos de pensadores brasileiros que tratam do ensino de Filosofia no Ensino Médio, bem como da fundamentação legal baseados nos documentos oficiais e diretrizes que norteiam a presença da disciplina da Filosofia no ensino médio.

Na UERN, os componentes curriculares como as Oficinas de Atividades Filosóficas, os Estágios Supervisionados, as Metodologias e os específicos na área da Filosofia permitem que o licenciando vá se inteirando do estudo e discussões com vistas ao seu futuro campo de trabalho, a escola. Aqui ele terá a oportunidade de conhecer de forma teórica e prática os desafios e necessidades inerentes ao exercício docente. Nessa perspectiva, avaliamos que um programa direcionado às práticas docentes como o PIBID veio 
valorizar e fortalecer ainda mais a reflexão e a intervenção no campo de atuação profissional dos nossos alunos.

Não imaginamos hoje um professor-pesquisador separado do professor atuante apenas na sala de aula, logo porque se torna inadmissível tal dicotomia absurda permitindo um erro em se tratando de prática docente. $\mathrm{O}$ professor não é aquele que "dá aulas" a uma plateia de receptores passivos. O conhecimento, em especial em Filosofia, tem que ser algo que está sendo construído, daí não caber a ideia de um filósofo que pesquisa e de um filósofoprofessor que somente ensina, já que este não é cumulativo. Hoje, professor não é só da sala de aula, mas, está envolvido nas diversas atividades que o faz ser um professor de verdade.

Assim, teremos que levar em conta toda uma construção que o envolve e ter consciência de que precisamos saber mais, conforme nos diz Freire (2004, p. 50)25: "onde há vida, há inacabamento. Mas só entre mulheres e homens o inacabamento se tornou consciente". Nossa preocupação em não ter uma educação pronta, de forma acabada, tem o intuito de percebermos que Filosofia está em permanente construção. "Pois quando se constrói, os frutos têm o sabor do mutirão do 'eu também fiz'". (SOUZA; CIRINO, 2012, p. 226) ${ }^{26}$.

É nessa perspectiva que poderemos vislumbrar o perfil do docentepesquisador, norteando suas ações no cotidiano, estando consciente de seu papel e em que chão estará pisando para não elaborar sua ação distanciada do contexto real. Afirmam Souza e Cirino (2012, p. 226):

Uma das formas de se obter essa formação permanente e
prática torna-se viável pela pesquisa que esteja em sintonia de
um contexto de mudança, contribuindo na formação pessoal
do profissional como também possa abrir-se ao novo sem ser
modista, mas olhando a dinamicidade da dimensão do
coletivo e da comunidade. Hoje, mais que antes com a
velocidade das inúmeras informações é que o professor não
deverá se limitar somente a "dar" suas aulas, visto que: "Não há
ensino sem pesquisa e pesquisa sem ensino" (FREIRE, 2004, p.
29). Portanto, o professor, mais que um reprodutor de

25 FREIRE, Paulo. Pedagogia da autonomia: saberes necessários á prática educativa. São Paulo: Paz e Terra, 2004.

${ }^{26}$ SOUZA, J.F.C. \& CIRINO, M. R. D. Formação docente e pesquisa: uma relação necessária? In: Dax Moraes, Éricka Janine, Isabela Pinheiro e Marcos Von Zuben (orgs.). Filosofia, Educação e Saúde - Interfaces. Mossoró: UERN, 2012. p. 212-233.

Revista Digital de Ensino de Filosofia - Santa Maria - vol.3. n.1 - jan./jun. 2017. 
conhecimentos, pode caracterizar-se (e, portanto, formar-se) como um produtor de conhecimentos. Na compreensão de Freire (2004, p. 29), é constitutivo da ação docente "a indagação, a busca, à pesquisa. O [...] que se precisa é que, em sua formação permanente, o professor se perceba e se assuma, porque professor, como pesquisador".

Percebemos então, que é necessário termos consciência e reflexão do nosso papel de formando e futuro formador. Não é possível dissociar a pesquisa do ensino já que uma permite ao outro o bom andamento, especialmente do ser docente.

O estudo realizado dentro do PIBID bem como a intervenção na escola conscientizou a todos os bolsistas da urgente aproximação teoria e prática, a procura por metodologias e um ensino inovador capazes de ser atraentes aos jovens do ensino médio. Com isso, adquiriram consciência de que o filósofo é uma pessoa de seu tempo, criativo no que pensa e faz.

Durante a vigência do subprojeto, fomentou-se o incentivo à produção científica como: produção de artigos, capítulos de livros e participação em eventos que abordassem a temática da docência em filosofia. E se priorizou a especificidade da Filosofia (PCN+ 2006, p. 44) 27: Ler textos filosóficos de modo significativos.

- Laboratórios de leitura e escrita de textos filosóficos;

- Aulas: instigar, debater, dialogar, construir e fazer juntos.

- Construção de planos de aulas sob a coordenação dos supervisores;

- Criação de produtos pedagógicos usados nas escolas e nas exposições de materiais pedagógicos que aconteceram nas Semanas de Filosofia de Caicó; nas JENFIC-Jornadas de Ensino de Filosofia de Caicó e na Feira de Materiais Pedagógicos (Campus Central - Mossoró);

- Participação nos Seminários Avaliativos que aconteceram em Mossoró-UERN; Caicó-EECCAM; Patu e Pau dos Ferros;

- Produção do livro: Formação Docente PIBID-UERN;

- Iniciado produção de Cartilha Didática com sugestões de roteiros de aulas;

27 BRASIL. Ministério da Educação, Secretaria de Educação Média e Tecnológica. PCN+ Ensino Médio: orientações educacionais complementares aos Parâmetros Curriculares Nacionais. Ciências Humanas e suas tecnologias. Brasília: MEC. SEMTEC, 2002.

Revista Digital de Ensino de Filosofia - Santa Maria - vol.3. n. 1 - jan./jun. 2017. 
- Teatro "Puxincói Filosófico";

- Criação e publicação de Cordéis com temas da filosofia;

- Participação em eventos: Recife, Mossoró, Natal, Pau dos Ferros e Caicó;

Todas essas ações não se deram separadas do chão da escola. Os bolsistas se integraram à vida das escolas parceiras e participaram dos eventos, das Semanas de Planejamento, da escolha do livro didático, da criação de "espaços" para o subprojeto nas escolas, participação nas ações promovidas pela escola, semanas de ciência, criação e execução de Planos de aulas aplicados em contra turno e nos momentos culturais celebrados pela escola. Durante todo esse período os bolsistas estiveram presentes seja aplicando atividades apontadas no subprojeto, seja vivendo a vida da escola. Assim, marcou a primeira experiência de uma intervenção e aproximação do ensino superior e ensino básico, o que rendeu muitos estudos e reflexões permitindo a continuidade ampliada da presença interativa da Universidade e da Escola.

Do desejo acalentado em 1968 até a sua presença marcante em Caicó e região, a Filosofia faz história no torrão do Seridó potiguar. Além disso, através dos seus egressos a presença da UERN se estende e alcança as cidades vizinhas a Caicó e outros Estados da federação brasileira. Os egressos, em sua maior parte, estão exercendo a docência nas escolas da rede básica; outros no ensino superior; alguns deram continuidade a formação em nível de pósgraduação lato e stricto senso. Para dar continuidade a essa história será necessário lutar pela melhoria das condições de trabalho no Campus CaicóCaC; pela formação e capacitação dos professores; por novos concursos; será necessário continuar lutando por um ensino público, gratuito e de qualidade. O Curso de Filosofia do Campus Caicó deve assumir a utopia e acalentar o sonho da pós-graduação stricto senso. O mestrado profissional28 e acadêmico em Filosofia possibilitará a formação continuada dos professores

28 O Curso de Filosofia do Campus Caicó sedia o Núcleo da UERN do Mestrado Profissional em Filosofia em rede com outras instituições nacionais, coordenado pela Universidade Federal do Paraná (UFPR). A primeira turma com 13 alunos começou em abril de 2017.

Revista Digital de Ensino de Filosofia - Santa Maria - vol.3. n.1 - jan./jun. 2017. 
de Filosofia da rede básica, o aperfeiçoamento e o aprimoramento da pesquisa em Filosofia no interior do Rio Grande do Norte.

\section{REFERÊNCIAS}

ALVES, Dalton José. A filosofia como matéria de ensino: história e questões metodológicas. Publ. UEPG Humanit. Sci., Appl. Soc. Sci., Linguist., Lett. Arts, Ponta Grossa, 17 (2): 177-187, dez. 2009. Disponível em: <http://www.revistas2.vepg.br/index.php/humanas/article/view/1771>.

BRASIL. Ministério da Educação, Secretaria de Educação Média e Tecnológica. PCN+ Ensino Médio: orientações educacionais complementares aos Parâmetros Curriculares Nacionais. Ciências Humanas e suas tecnologias. Brasília: MEC. SEMTEC, 2002.

BRASIL. Lei $n^{\circ}$ 13.415, de 16 de fevereiro de 2017. Disponível em: <http://www.planalto.gov.br/ccivil_03/_Ato20152018/2017/Lei/L13415.htm\#art 1 > Acesso em: 15/06/2017 (Altera as Leis nos 9.394, de 20 de dezembro de 1996, que estabelece as diretrizes e bases da educação nacional, ...).

CAMPANER, Sônia. Filosofia: ensinar e aprender. São Paulo: Saraiva, 2012.

CERLETTI, Alejandro. O ensino de filosofia: como problema filosófico. Belo Horizonte: Autêntica, 2008.

FOGEL, Gilvan, Que é Filosofia?: Filosofia como exercício de finitude. Aparecida (SP): Ideias e Letras, 2009.

FREIRE, Paulo. Pedagogia da autonomia: saberes necessários á prática educativa. São Paulo: Paz e Terra, 2004.

ROCHA, Jaime Vieira (Bispo diocesano). Liber vi spiritus (Liberdade pela força do espírito). Trilhas filosóficas. Ano 1. N 1. Jan/Jun 2008, p. 134-139.

RODRIGO, Lídia Maria. Filosofia em sala de aula: teoria e prática para o ensino. 2 ed. Campinas: Autores Associados, 2014. (Coleção formação de professores)

SEVERINO, Antônio Joaquim. Como ler um texto de filosofia. 4ed. São Paulo: Paulus, 2013.

SEVERINO, Antônio Joaquim. Filosofia para a vida. Filosofia Ciência e Vida, São Paulo, v. 08, n. 98, pág. 05-13, set. 2014. Entrevista concedida a Jorge da Cunha Dutra e Fábio Antônio Gabriel.

SOFISTE, J.G. Sócrates e o ensino de Filosofia. Investigação dialógica numa pedagogia para a docência de Filosofia. Petrópolis, RJ: Vozes, 2007.

Revista Digital de Ensino de Filosofia - Santa Maria - vol.3. n.1 - jan./jun. 2017. 
SOUZA, J.F.C. \& CIRINO, M. R. D. Formação docente e pesquisa: uma relação necessária? In: Dax Moraes, Éricka Janine, Isabela Pinheiro e Marcos Von Zuben (orgs.). Filosofia, Educação e Saúde - Interfaces. Mossoró: UERN, 2012. p. 212-233.

SOUZA, Sônia Maria Ribeiro de. A filosofia no ensino médio: Uma (re)leitura a partir dos PCNs. In: GALLO, Sílvio; DANELON, Márcio; CORNELLI, Gabriele (orgs). Ensino de Filosofia: Teoria e prática. ljuí (RS): UNIJUÍ, 2004. pág. 161-181.

XAVIER, João Batista. Discurso em Homenagem aos formandos do Curso de Licenciatura Plena em Filosofia UERN/Caicó - 28/07/2005. Trilhas filosóficas. Ano 1. № 1. Jan/Jun 2008, p. 128-133.

XAVIER, João Batista. Discurso proferido por ocasião da homenagem recebido do Curso de Filosofia/Caicó 03/12/2012. In. BRITO, Sueny Nóbrega Soares; CIRINO, Maria Reilta Dantas; SOUZA, José Francisco de Souza; TEIXEIRA NETO, José. Anais. $\vee$ Semana de Filosofia do Campus Caicó. II JENFIC Jornada de Ensino de Filosofia de Caicó. Mossoró-RN: Edições UERN, 2013, p. 915. Disponível em: <http://www.vern.br/controledepaginas/fisolofia-caicoeventos/arquivos/2087anais_v_semana_de_filosofia.pdf>. 